\title{
EL ORIGEN DE LA IDEA DE VACÍO EN GRECIA
}

\author{
Carlos MEGINO RODRIGUUEZ \\ Departamento de Filosofia. Facultad de Filosofla y Letras \\ Universidad Autbnoma de Madrid
}

\begin{abstract}
Toln au)toln del tro/pon u(polhpte/on eiånai tou= fusikou = qewrh=sai kail perì kenou=, ei ${ }^{1}$ eÁstin $h \ddot{A} \mathrm{mh} /$, kail $\mathrm{pw}^{1} / 2 \mathrm{j}$ eÁsti, kaiì ti ${ }_{\zeta}$ e)stin, wDsper kail perì to/pou. Aristóteles, Fisica, 213a12-14.
\end{abstract}

Resumen: Entre los numerosos conceptos de los que somos, de alguna medida, tributarios de Grecia, creemos que merece una atención especial, sobre todo en un contexto de investigación filosofica, el concepto de "vacio". Por ello, pretendo con este artículo ofrecer unas pautas para la comprensión del origen y significado de la noción de vacio entre los griegos, analizando el término del que se dotaron éstos para designar dicho concepto: keno j (como substantivo: tol keno;n), desde Homero hasta la especulación presocrática que culmina con la teoría atomista de Leucipo y Demócrito, en la que la idea de vacio tiene un papel central.

Abstract: Among the numerous concepts which we owe to the greeks, the concept of "vacuum" is worth thinking about in philosophical meaning. In this article, then, I want to see what was the origin and meaning of the idea of vacuum among the greeks, by means of analysis of the word what the greeks use to designate these concept: keno jj (as a substantiv: tol keno;n) from Homer to the theory of greek atomists, in which the idea of vacuum is central.

Entre el considerable número de conceptos que los griegos concibieron y que, con más o menos avatares, legaron al acervo filosófico occidental, hay uno que nos llama la atención porque, a pesar de que ha llegado a constituir un 
pilar en la cosmovisión física moderna, no ha sido especialmente tratado por los estudiosos del mundo griego. Nos referimos al concepto de "vacío» ${ }^{1}$.

Para nosotros el término «vacío» tiene, grosso modo, dos sentidos principales ${ }^{2}$ : el primero, es el sentido que podríamos llamar intuitivo, cotidiano, aquél que está más consagrado por el uso corriente, según el cual lo "vacío" se define como la ausencia de contenido, es decir, como una falta o carencia de algo que podría ocupar un determinado espacio físico y que, de hecho, no lo hace. En este sentido, decimos que una habitación, una botella, una carpeta, etc... está "vacía" cuando carece del tipo de cosas que normalmente contiene, como, por ejemplo, personas, agua o folios, no incluyendo aquellas otras que no echamos de menos en dichos espacios, como el aire ${ }^{3}$. Se trata, por tanto, de un vacío relativo.

El segundo sentido es el que podríamos llamar "físico», según el cual el vacío es el espacio que no contiene ninguna materia perceptible por medios físicos o químicos o, dicho de otro modo, aquel estado físico en el que todas las magnitudes que pueden ser observadas, no sólo las realidades materiales, sino también lo que llamamos energía, como las ondas electromagnéticas, tienen un valor casi nulo. Decimos casi, porque, como se sabe, el vacío absoluto no existe como tal en el universo ya que, cuanto menos, existe una radiación de fondo de rayos gamma bastante uniforme sea cual sea la dirección en la que observemos ${ }^{4}$.

Vemos, pues, que para el hombre moderno el concepto de "vacío» tiene fundamentalmente estos dos sentidos, pero, cabe preguntarse, ¿cuál era la con-

1 Se puede encontrar un breve sumario sobre la evolución de este concepto en la Grecia antigua en J. O. URMson, The Greek Philosophical Vocabulary, Londres, Duckworth, 1990, s.v. kenos, y F. E. Peters, Greek Philosophical Terms. A Historical Lexicon, N. York, N. York University Press, 1967, s.v. kenós. Para una visión histórica más amplia del vacío como concepto filosófico, cf. por ej., P. EDWARDS (ed.), The Encyclopedia of Philosophy, 8 vols + Supl., N. York, Crowell Collier and McMillan, 1967, vol. 8 s.v. vacuum.

2 Sobre estos sentidos de "vacío", cf. por ej., P. FoulquiE, y R. SAINT-JeAn, Dictionnaire de la langue philosophique, 2." ed., Paris, Presses Universitaires de France, 1969, s.v. vide, A. JACOB (ed.), Les Notions philosophiques. Dictionnaire, 5 vols., París, Presses Universitaires de France, 1990, s.v. vide.

3 Este punto de vista es perfectamente definido por Descartes, cuando dice (Principes, II \$17): Ainsi, pour ce qu'une cruche est faite pour tenir de l'eau, nous disons qu'elle est vide lorsqu'elle en contient que de l'air ( Así, puesto que un cántaro está hecho para contener agua, nosotros decimos que aquél está vacío cuando no contiene nada más que airen).

4 Sobre la concepción físico-filosófica moderna del vacío, cf. por ej., S. SAUNDERS y H. R. Brown (eds.), The Philosophy of Vacuum, Oxford, Clarendon Press, 1991. 
cepción griega del vacío? ¿Coincidía o no con la nuestra? Y si es así, ¿hasta qué punto podemos considerarla un precedente de nuestra noción de vacío?

Para intentar dar una respuesta a estas cuestiones nos proponemos dilucidar la concepción griega del "vacío» desde Homero hasta Demócrito, haciendo un análisis semántico del vocablo arquetípico con el que se dotaron los griegos para designar dicho concepto: keno j (como substantivo: tol keno

Si buscamos el origen indoeuropeo del término keno $j^{5}$ (el griego homérico oscila entre esta forma, el jónico keino $j$ y kene $(F) o_{j j} j$, mientras que el chipriota ofrece keneu(F)o $o_{j}$ ), cuya forma originaria debía ser ${ }^{*} k_{e n F o} j$, nos encontramos con una posible raíz *ken-, que sólo se encuentra representada en el armenio sin, "vacío, vano", lo cual sólo nos confirma el mismo sentido originario de "vacuidad", "ausencia de contenido".

Esta acepción es fácilmente rastreable en los primeros testimonios textuales. Así, en Homero nos encontramos con que keno jj (más frecuente keneo jj, keino jj) designa la cualidad de lo que carece del contenido que le es propio o que se espera que tenga. Por ejemplo, en Il. II 298, IV 181, Od. X 42, XV 214, keno $j$ califica la ausencia de botín, concibiéndolo como el contenido que debería llenar un determinado espacio, como el que ofrecen las naves o las manos. De forma parecida ocurre en $I l$. III 376, donde se alude al yelmo de Paris que, arrancado por Menelao, se encuentra "falto" de la cabeza del héroe troyano. Se trata, por tanto, de la misma concepción relativa del «vacío" que tenemos nosotros cuando usamos el término en su acepción más usual. Una concepción que reaparece posteriormente de forma recurrente, por ejemplo, en Esopo (El avaro, 344; El pastor y el mar, 311; La golondrina y la serpiente, 347, etc.), en Esquilo (Siete contra Tebas, 353), en Sófocles (Traquinias, 495), en Eurípides (Ión, 1412), en Aristófanes (Aves, 503), en Jenofonte (Anábasis, III 4.20, IV 8.18), en Platón (República, 370 e- 371 a) etc...

De todos modos, este no es el único significado de keno jj en Homero, ni, de hecho, en la literatura posterior. Hay que notar que dicho término se

5 Sobre la etimología de kenojj, cf. P. Chantraine, Dictionaire etymologique de la langue grecque. histoire des mots, París, Ed. Klincksieck, 1983, s.v.; H. FRISK, Griechisches Etymologisches Wörterbuch, Heidelberg, Carl Winter Universitätsverlag, 1960, s.v.; Alois Walde, Vergleichendes Wörterbuch der Indogermanischen Sprachen, Berlín y Leipzig, Ed. Walter de Gruyter \& Co., 1930, s.v. *ken-; Julius Pokorny, Indogermanisches Etymologisches Wörterbuch, Munich, Francke Verlag, 1959, s.v. *ken-. 
entiende también, en sentido derivado, como la falta subjetiva de importancia, utilidad o efecto que tiene una cosa, como las palabras ( $O d$. XXII 249), una esperanza irrealizable (Hesíodo, Trabajos y Dias, 498; Simónides, fr. 542 Page; Esquilo, Persas, 804; Píndaro, Nemea, VIII 45), una aspiración frustrada (Pínd., Olimpica, X 93) o un pensamiento inútil (Pínd., Nem., IV 40; Euríp., Hécuba, 824; Aristóf., Ranas, 530). Asimismo, llega a calificar a aquél que carece de entendimiento o sensatez (Pínd., Ol., III 45; Sófocles, Ed. Col., 931). Se trata, pues, de una noción psíquica de "vacío", más próxima a lo que podríamos denominar "vano", que responde a la convicción personal del sujeto de que lo que describe se caracteriza por su "carencia", que, en este caso, es de una cualidad abstracta.

Pero el uso de keno ¿j que más interesa para nuestro propósito entronca más bien con el que hacíamos referencia en un principio, el de ausencia de contenido relativo en un determinado espacio. Se trataría, por tanto, de una noción espacial del vacío, en la que éste se concibe como la cualidad de aquel lugar definido por unos límites cuya característica fundamental es la oquedad, entendida ésta como la falta de todo cuerpo perceptible a simple vista. Es, pues, un concepto de vacío que se deriva de la experiencia cotidiana, basado en la percepción sensible y que, por tanto, se fundamenta en la negación de que el aire sea susceptible de ocupar un lugar.

A partir de esta noción de "vacío», la filosofía presocrática va a construir un concepto cuya característica primera y más evidente será la de configurarse como una especie de elemento propio y con entidad real, y no ya una simple cualidad de las cosas. En este sentido, el adjetivo keno jj se sustantiva, pasando a ser tol kenǫn, "el vacío". Veamos, pues, qué entiende la filosofía griega por keno:̨n en tanto elemento cosmológico.

No está claro cuándo aparece la idea cosmológica de vacío en la especulación filosófica. Según Kirk y Raven ${ }^{6}$, parece una invención eleática; sin embargo, en el poema de Parménides no se hace ninguna mención expresa del vacío, aunque sí cabe la posibilidad de que, a pesar de que no se usara la palabra kenǫn, sí subyaciera esta idea en la concepción parmenídea del no-ser. De hecho, cuando Parménides habla de la "nada» (mhdeln o ou)dęn) como aquello de lo que es

6 Cf. G. S. KiRK, J. E. RAvEN, M. SCHOFIELD, Los filosofos presocráticos, $2 .^{2}$ ed., trad. esp., Madrid, Gredos, 1987, p. 479. 
imposible la predicación ontológica, es decir, aquello que carece de realidad efectiva o existencial ${ }^{7}$, parece que tiene en mente lo mismo que sus sucesores llamarán "vacíon: el ámbito del absoluto no-ser, aquello que está más allá de los límites del ser. En efecto, al conferir a todo lo que es un determinado límite, Parménides está admitiendo implícitamente un entorno externo, al que llama «nada» y que se define en relación al ser ${ }^{8}$. Parménides niega su realidad existencial y ontológica, pero no puede negar su necesidad lógica. Como dice A. Bernabé, «de la negación de la posibilidad de una predicación negativa como procedimiento lógico (es decir, de la imposibilidad de «ser no es" y de "no ser es») se llega a la afirmación de que una predicación negativa equivale a una afirmación de no existencian" ${ }^{9}$. Es decir, la predicación del ser implica la del no-ser, existiendo la misma necesidad lógica tanto de una como de otra; aunque se pueda decir que la "nada» o el "vacío" no es o no existe (lo que en griego viene a ser lo mismo) subyace una noción de lo que es, aunque éste sea negativa. Por tanto, y según nuestra interpretación, para Parménides el no-ser sería el contrapunto ontológico del ser, mientras que el vacío, como idea implícita, sería su contrapunto cosmológico.

Esta deducción del vacío eleático como lo carente de ser y, por tanto, identificable con el "no-ser" o la "nada", por un lado, y como un cierto ámbito que está más allá de los límites del ser, por otro, tiene su confirmación en Meliso de Samos, filósofo jonio conocido como continuador y defensor del sistema parmenídeo. Meliso asume la distinción parmenídea entre lo que es y lo que no es. De lo primero, adopta todas las características aducidas por Parménides: que es uno, eterno, homogéneo, lleno, ingénito, imperecedero, inmóvil, etc..., salvo una, la de que es finito; mientras que de lo segundo, es decir, del "no-ser" o la "nada", afirma que es lo "vacío" ${ }^{10}$. Por tanto, Meliso usa ya explícitamente el término kenǫ̨n para referirse a lo mismo que Parménides concebía como aquello que carece en

728 B 6 DIELS-KRANZ: Es necesario que sea lo que se diga y se conciba; pues el ser es, mientras que la nada no es. Advertimos que usamos la letra cursiva para citar fragmentos literales, mientras las comillas ( $* m$ ) para citar los testimonios. Las traducciones de las citas son mías salvo mención expresa en contrario.

8 Cf. 28 B 8, 29 DK: Manteniéndose lo mismo y en lo mismo, yace por st mismo y así permanece firme donde está, pues la poderosa Obligación lo mantiene en las prisiones del limite que lo encierra de ambos lados... que nada bay ni babrá fuera de lo que es [o, lo que es lo mismo, "fuera del ser sólo hay el no-ser, la nada"] trad. de A. Bernabé.

9 Cf. A. Bernabe, De Tales a Demócrito. Fragmentos presocráticos, Madrid, Alianza, 1988, p. 153 (la cursiva es mía).

1030 B 7 DK: No hay ningún vacio, pues lo vacio no es nada y la nada no podria ser [trad. de Fco José Olivieri]. 
absoluto de ser y de lo que, por eso, sólo puede predicarse el no ser. De esta forma, Meliso deja establecida una primera forma de concebir el vacío: la que se deriva del establecimiento de su carácter óntico (por vía negativa).

Perc, como ocurría con Parménides, este carácter óntico del vacío como lo que no es implica una condición cosmológica derivada, que es la de considerar el vacío como un lugar o espacio aparte del ámbito del ser, pero que, por definición, lo delimita. Esta concepción "local» del vacío se refleja claramente en los argumentos de Meliso para demostrar la imposibilidad del movimiento y la infinitud del ser. En el primer caso, cuando dice que si el ser se moviera, tendría que haber algún vacío hacia el cual pudiera desplazarse ", pero que, al no existir el vacío, el movimiento es imposible. Aquí aparece la concepción básica de Meliso sobre el vacío y, en palabras de Kirk y Raven, "una de las nociones clásicas del pensamiento físico griego" ${ }^{12}$, que es la del vacío como condición previa del movimiento. En otras palabras, el vacío sería, en este sentido, el espacio libre y carente de ser, es decir, de corporalidad o contenido material, lógicamente necesario para postular la posibilidad del movimiento. En el segundo caso, Meliso muestra esta misma idea de vacío cuando afirma que si el ser no fuera infinito tendría que limitar con el vacío ${ }^{13}$. Por tanto, el concepto de límite configura una vez más la idea cosmológica del vacío como espacio externo cuya existencia Meliso, al igual que Parménides, niega ${ }^{14}$, pero cuya necesidad lógica tiene que admitir.

1130 A 5 DK (Pseudo Aristóteles, Sobre Meliso, Jenófanes y Gorgias, 974a): "Siendo eterno, infinito, totalmente homogéneo, lo uno es inmóvil, pues no podría moverse si no fuera retirándose hacia algo. Pero es necesario que se retire yendo hacia lo lleno o hacia lo vacío; ahora bien, de éstos, uno [lo lleno] no podría recibirlo, y el otro [lo vacío] no es nada"; 30 B 7 DK: Tampoco (lo que es) se mueve, pues no tiene lugar alguno donde retirarse, sino que está lleno. Si hubiese un vacío, podría retirarse al vacto, pero, como el vacio no es, no tiene a dónde retirarse, 30 A 8 (Aristóteles, Física, IV 6, 213b): "Meliso demuestra que el todo es inmóvil a partir de lo siguiente: si se moviese, dice, necesariamente habría un vacío, pero el vacío no es una de las cosas que son" ; (Aristóteles, Sobre la generación y la corrupción, I 8, 325a): "A algunos de los antiguos les parecía que lo que es, es necesariamente uno e inmóvil, pues por un lado no existe el vacío y, por el otro, no sería posible el movimiento al no haber vacío separado".

12 Op. cit., p. 554.

1330 A 8 (Aristóteles, Sobre la generación y la corrupción, I 8, 325a): «A partir de estos argumentos, algunos [en referencia especial a Meliso], yendo más allá de la percepción y desatendiéndola en la idea de que se debe seguir la razón, dicen que el todo es uno, inmóvil e infinito: en efecto, [de no ser infinito] el limite confinaria con el vacíon.

14 A los cuales habría que añadir también a Zenón de Elea, según el testimonio de Diógenes Laercio, IX 29 (29 A 1 DK): «[Zenón] opinaba lo siguiente: que hay mundos y que no hay vacío". 
Y es precisamente la idea de límite la que sirve como fundamento a una concepción del vacío estrechamente relacionada con aquella noción más usual, ya vista, que lo entendía como un lugar definido por unos límites y caracterizado por la oquedad. Nos referimos a lo que podríamos llamar "vacío interno", es decir, el intervalo espacial carente de cualquier tipo de contenido que delimita las cosas que son y, por tanto, que constituye el fundamento no sólo del movimiento, sino también de la multiplicidad y el cambio. Esta es la concepción que más tradición tiene en la filosofía presocrática y que posiblemente quepa considerar en mayor medida como origen, fundamento y correlato de esa otra concepción externa, cosmológica del vacío.

Para introducirnos en ella, retomemos esa noción no técnica de vacío a que acabamos de hacer alusión. Como vimos más arriba, esta idea de vacío se caracterizaba por derivarse de la percepción sensible, que considera "hueco" cualquier espacio delimitado que carezca de contenido material perceptible, excluyéndose el aire ${ }^{15}$. Pero esta noción, como pronto comprendió la especulación filosófica, no responde en realidad a la exigencia lógica que comporta la idea de vacío, que es la de ausencia absoluta de contenido, sea cual sea éste. En este sentido, podríamos decir que el concepto técnico, filosófico de "vacío", el toł keno`n, nace en cuanto se establece de forma explícita la diferencia entre vacío y aire, entre oquedad relativa y absoluta.

Parece que la prioridad en la introducción del concepto de vacío como algo distinto del aire y, por tanto, de la idea común de "vacío", hay que otorgársela a Anaxágoras y Empédocles ${ }^{16}$. El primero, intentaba demostrar que el vacío no existe mediante la descripción de lo que sucede en una clepsidra ${ }^{17}$, cuando

15 En palabras de Aristóteles (Física, IV 6, 213 a 27-31): "Pero lo que la gente entiende por vacio es más bien una extensión (o intervalo) en la que no hay ningún cuerpo sensible $y$, como creen que todo cuanto es, es corpóreo, afirman que el vacío es aquello donde no hay absolutamente nada, y por eso lo que está lleno de aire [para ellos] está vacío" [trad. de G. R. de Echandía].

16 Por lo menos, así lo entienden autores como W. BURKERT, Weisheit und Wissenschaft; Studien zu Pythagoras, Philolaos und Platon, Nuremberg, 1962, p. 33 n. 108, y Kirk y Raven, op. cit., p. 555 n. 2.

17 No se trata de un reloj de agua, sino de una pequeña vasija metálica con un cuello estrecho y abierto por arriba y llena de orificios por debajo al modo de una regadera, que era empleada para trasvasar líquidos. 
ésta se sumerge en el agua tapando la abertura superior ${ }^{18}$. Como el agua no penetra en su interior, Anaxágoras dedujo que era la presión del aire en los orificios inferiores de la clepsidra la que causaba la exclusión del agua, con lo que hacía patente, asimismo, que la "corporalidad" del aire, mostrada por la presión que ejerce sobre el agua, negaba la creencia popular de que la oquedad de un recipiente suponía que éste estaba "vacío". El aire, por tanto, era diferente del puro vacío ${ }^{19}$, que como tal no existe. A la misma conclusión llega Anaxágoras tanto en su descripción de la respiración de los animales ${ }^{20}$, como en su explicación de la inmovilidad de la tierra ${ }^{21}$. De ello se deduce que para el filósofo de Clazómenas, el vacío no existe porque supone un espacio de absoluta incorporalidad que es negado por la evidencia empírica, incluso en aquellos casos, como los de los recipientes huecos, en los que la gente común cree que sí existe porque no lo distinguen del aire.

18 Cf. 59 A 69 (Aristóteles, Problemas, XVI 8, 914b-915a): "La causa de los fenómenos que suceden en la clepsidra parece ser la que dice Anaxágoras. En efecto, el aire encerrado en ella es causa de que el agua no penetre cuando el tubo está tapado [en su abertura superior] . . . [El aire], sea impulsado o moviéndose por sí mismo sin ser compelido, se mueve por naturaleza en línea recta, tal como los demás elementos. Si la clepsidra se sumerge en forma inclinada, [el aire] manteniendo su curso recto, es expelido por el agua a través de los orificios opuestos a los [sumergidos] en el agua y, al irse, el agua ingresa. Si en cambio la clepsidra se sumerge en forma recta en el agua, [el aire] no puede seguir su curso recto porque las partes superiores están obstruidas, y permanece en torno a los primeros orificios, pues no puede comprimirse en sí mismo. Y la prueba de que el aire, cuando no se puede mover, es capaz de excluir al agua, está en lo que sucede en la clepsidra" [trad. de C. Eggers Lan].

19 No importa para conocer la concepción del vacío que tenía Anaxágoras que éste consiguiera verdaderamente o no demostrar que el aire es algo distinto del vacío y que éste no existe, frente a la opinión de Aristóteles, que pensaba que aquél había errado en su intento de demostración: (Ftsica, IV 6, 213a): "Los que intentan demostrar que [el vacio] no existe, no rechazan lo que los hombres entienden al decir 'vacío', sino que se equivocan al hablar: así Anaxágoras y los que refutan de este modo [la existencia del vacio]. Lo único que demuestran, en efecto, es que el aire es algo retorciendo odres, y prueban también que el aire es resistente, encerrándolo en clepsidras" [trad. de C. Eggers Lan].

2059 A 115 (Aristóteles, Acerca de la respiración, 470b-471a): “Anaxágoras y Diógenes, quienes afirman que todos [los seres vivos] respiran, dicen de qué modo respiran los peces y las ostras. Y Anaxágoras dice que los peces, cuando expelen el agua a través de las agallas, respiran atrayendo el aire que se genera en la boca, porque no puede haber vacío" [trad. de $C$. Eggers Lan].

2159 A 42 (Hipólito, Refutación de todas las herejtas, I 8, 3): "La tierra tiene forma plana y se mantiene suspendida por su tamaño, porque no hay vacío y porque el aire, que es muy firme, lleva a la tierra como una cabalgadura" [trad. de A. Bernabé]. 
En cuanto a Empédocles, ya Aristóteles señaló su coincidencia con Anaxágoras en la negación del vacío ${ }^{22}$, coincidencia que se extiende incluso al recurso de evocar el uso de la clepsidra, que, a Empédocles, le sirve para describir cómo entiende el proceso de la respiración ${ }^{23}$. Para él, ésta consiste en un movimiento de vaivén entre el aire y la sangre a través de los poros de la superficie del cuerpo. Cuando la sangre se retira de los poros, el aire entra y se produce la inspiración, pero cuando sucede al revés, el aire sale y el sujeto espira. La cuestión sobre el vacío estriba en que, como Anaxágoras respecto de la clepsidra, los orificios de entrada y salida (en este caso los poros de la piel ${ }^{24}$ ), nunca están vacíos, sino que el lugar que deja libre la sangre lo ocupa el aire y al contrario ${ }^{25}$. Con ello, pues, se verifica la distinción entre aire y vacío, siendo lo primero un elemento sutil pero corpóreo, y lo segundo la pura y absoluta carencia de ser, razón por la cual no puede existir ${ }^{26}$.

2259 A 68 (Aristóteles, Acerca del cielo, IV 2, 309a): «Algunos de los que niegan que exista el vacío no se han pronunciado con precisión acerca de lo liviano y lo pesado, como Anaxágoras y Empédocles» [trad. de C. Eggers Lan].

2331 B 100 DK: $Y$ asi es como todos inspiran y espiran. Hay en todos, escasos de sangre, unos tubos de carne que se extienden por el confin del cuerpo. Sobre sus bocas se encuentra, horadada por apretados orificios, la superficie más externa de la piel, de parte a parte, de suerte que a la sangre la guardan, mas al éter le queda abierta via libre para el paso. Así que, cuando la tierna sangre se retira, irrumpe el éter borbotando en furiosa oleada, mas cuando salta aquella hacia arriba, el animal espira. Lo mismo que una niña que con una clepsidra de bronce refulgente está jugando: cuando, con la boca del tubo puesta en su grácil mano, la baña en el tierno cuerpo del agua que luce como plata, en la vasija no penetra lluvia alguna, sino que se lo impide la masa de aire que se abate desde dentro sobre los apretados orificios, hasta que abre ella la tapa a la apretada corriente. Y es entonces cuando penetra, al flaquear el aire, agua en la debida cantidad. [trad. de A. Bernabé] Hay que notar que aquí la palabra ai)qh $h_{c}$, "éter» no hace referencia a un tipo de fluido especial y sutil, sino que es una denominación poética del "aire", lo cual responde al talante poético de Empédocles, quien gusta de una terminología variada y metafórica para hacer referencia a los cuatro elementos principales: aire, agua, tierra y fuego.

24 Siguiendo la interpretación que entiende el $r$ (inw. ${ }^{2} n$ del fragmento 100 arriba citado de Empédocles como genitivo de r(ino $j$, "piel" y no de $r(i, j$, "nariz».

2531 A 87 (Filópono, Sobre la generación y la corrupcion, 178, 2): «Sabemos que los que suponían la existencia de los poros no los concebían vacíos, sino llenos de un cuerpo más sutil que el aire. Pues el vacío es distinto que éste. Los poros son distintos del vacio, ya que no decían que los poros estuvieran vacíos" [trad. de E. La Croce]. Que Filópono hable de "un cuerpo más sutil que el aire" se debe seguramente a que entiende el ai) $q h_{\grave{\zeta}}$ de Empédocles como algo distinto del aire, lo cual, como hemos visto en la nota anterior, no es correcto. Por otra parte, Aristóteles sí parece atribuir a Empédocles la asunción de la existencia del vacío, cuando dice que, para evitar que haya sólo vacío, es necesario que los cuerpos que están en contacto sean indivisibles y que entre ellos esté el vacío, que Empédocles llama "poros" (Sobre la generación y la corrupción, I 8, 325b).

2631 B 14 DK (Pseudo-Aristóteles, Sobre Meliso, Jenofanes y Gorgias, 2, 976 b): "Y del mismo modo dice Empédocles que las cosas siempre están en movimiento, combinándose per- 
Así, una vez establecida la distinción entre aire y vacío, y entendiéndose éste como ausencia absoluta de contenido corpóreo (en sentido eleático, carencia de ser, equivalente al "no-ser" o la "nada»), se abre el camino, como hemos visto con Meliso, para su consideración locativa y, dentro de ésta, para su concepción como intervalo espacial hueco que delimita las cosas. De hecho, esta noción de "vacío interno" y aquella otra ya aludida de "vacío externo o cosmológico" son las dos caras de una misma moneda y suelen aparecer juntas en un mismo autor.

Esto se aprecia claramente en los pitagóricos, a los que podemos considerar como los primeros filósofos que aceptan la existencia del vacío. Según la información que poseemos de ellos, proveniente de Aristóteles, el vacío era concebido como una realidad óntica, coexistente en lo ilimitado con el aliento (pneu=ma), cuya función principal era la de separar y delimitar el continuo, y en, especial, los números ${ }^{27}$ que, como se sabe, tenían para los pitagóricos un doble carácter aritmético y geométrico, constituyendo, en tanto magnitudes extensas, los principios básicos sobre los que se constituía la realidad ${ }^{28}$.

Esta concepción delimitadora del vacío, estrechamente relacionada con su función de condición de posibilidad de todo movimiento o cambio, la encon-

petuamente, y que nada existe de vacío. Se expresa así: $Y$, del todo, nada hay vacio, ¿de dónde, pues, podría provenirle algo más?h? [trad. de E. La Croce]; 31 A 86 (Teofrasto, Sobre Las sensaciones, 13): “¿Están los poros vacios o llenos? Pues si están vacíos cae en contradicción consigo mismo, porque afirma que el vacío no existe en absoluto; si en cambio están llenos, entonces los animales experimentarían sensaciones siempres [trad. de E. La Croce].

2758 B 30 (Aristóteles, Física, IV 6, 213b22): "También los pitagóricos decían que el vacío existe y que penetra en el universo mismo a partir de lo ilimitado, como si éste inhalara aliento y vacío. Éste último delimita las naturalezas, como si el vacío fuera lo que separa y delimita lo continuo; y afirmaban que está primariamente en los números, pues el vacío delimita la naturaleza de éstos"; (Estobeo, Antología, I 18, 1 c): "En el primer libro de su obra Sobre la filosofia de Pitágoras dice [Aristóteles] que el universo es uno y que desde lo ilimitado son introducidos en él el tiempo, el aliento y el vacío, que delimita constantemente los emplazamientos de cada una de las cosas".

28 Como dice A. Bernabé (op. cit., p. 73): «Los principios básicos de esta teoría (la pitagorica) eran la ecuación de las cosas con los números y el dualismo. Respecto de la primera afirmación,, es de señalar cómo los pitagóricos, a partir del descubrimiento de que tras algunas realidades subyacen principios matemáticos, generalizaron este principio hasta el extremo de postular que todo eran números; en otros términos, los números no sólo constituían el plan sobre el que se organizaba el mundo (hoy estamos dispuestos a afirmar que, efectivamente, el cosmos se organiza de acuerdo con relaciones numéricas), sino que consideraron que las unidades tienen magnitud corpórea y, por tanto, configuran el mundo también de forma materialn. Cf. también, Aristóteles, Metafisica, 1080 b 16, 1090 a 20. 
tramos, como ya vimos, en Meliso, a quien hacemos ahora referencia para ilustrar esta noción de "vacío interno" que, en este filósofo, se halla también en conexión con el problema de la multiplicidad de los seres. En efecto, la única posibilidad de que el Ser, que es uno, simple, lleno y homogéneo, permita la multiplicidad en su seno es que exista un vacío separador de las cosas en virtud del cual podamos decir que una cosa es distinta de otra. Posibilidad que Meliso, como buen parmenídeo, niega tajantemente ${ }^{29}$.

Finalmente, existe una última opción para entender el vacío derivada de ésta, que es la de suponerlo como una especie de intersticio no separable en el interior de los propios cuerpos, cuya existencia sería condición de posibilidad de lo denso y lo raro. La prioridad de esta conexión entre vacío interior no separado y la densidad y la rarefacción de los cuerpos parece que hay que concedérsela a Juto, un filósofo pitagórico al decir de Simplicio (Comentarios a la Física, 683, 24), que dataría, según Kirk y Raven ${ }^{30}$, de principios del siglo $\mathrm{V}$ a. C. Este Juto, conforme al testimonio de Aristóteles, pretendía demostrar que lo raro y lo denso eran la prueba de la existencia del vacío ${ }^{31}$.

Un argumento que es recogido por el propio Meliso, quien, no obstante, se sirve de él para negar también la existencia del cambio que supone la densidad y la rarefacción, una vez que rechaza la premisa mayor, que es la realidad óntica y existencial del vacío ${ }^{32}$.

29 30 A 8 (Aristóteles, Sobre la generación y la corrupción, I 8, 325a): «A algunos de los antiguos les parecía que lo que es, es necesariamente uno e inmóvil, pues por un lado no existe el vacío y, por el otro, no sería posible el movimiento al no haber vacío separado. Ni habría tampoco multiplicidad, no existiendo nada que dividan.

30 Op. cit., p. 554, n. 1.

31 Cf. Aristóteles, Física, IV 9, 216 b 22: “Hay algunos que creen que gracias a lo raro y a lo denso resulta manifiesto que existe un vacío. Pues si no existiesen lo raro y lo denso, las cosas no podrían contraerse ni ser comprimidas. Pero, si esto no aconteciera, no existiría el movimiento en absoluto o 'el universo se hincharia', como dijo Juton.

3230 B 7 DK (Simplicio, Física, 112, 8-10): "Tampoco podría [lo que es] ser denso y raro, pues lo raro no puede estar tan lleno como lo denso, sino que lo raro precisamente llega a ser más vacío que lo denso. Hay que hacer, pues, esta distinción entre entre lo lleno y lo no lleno: si algo hace lugar a algo o lo admite, no está lleno; si, en cambio, ni hace lugar ni lo admite, está lleno. En consecuencia, es necesario que esté lleno si no hay vacío. Y si, por tanto, está lleno no se mueve»; (Simplicio, Fisica, 104, 8-12): "Es, en efecto, imposible que lo raro esté lleno del mismo modo que lo denso, pues lo raro resulta más vacío que lo denso; pero el vacío no existe. Que lo que es esté lleno o no, es preciso distinguirlo porque admita o no alguna otra cosa: si no la admite, está lleno, pero si la admitiera, no estaría lleno. Por tanto, si no hay vacío, es necesario que esté lleno". 
En resumen, podemos decir que la reflexión filosófica presocrática referente al vacío que hemos analizado hasta ahora, lo entiende de cuatro formas distintas, pero estrecharnente vinculadas entre sí: la primera, es la de Parménides, que concebiría el vacío como lo carente absolutamente de ser, identificable con el "no-ser" o la "nada», por un lado, y como un cierto ámbito que está más allá de los límites del ser, por otro. Esta concepción del vacío vendría secundada por Meliso, quien la precisa y completa en otros tres sentidos: primero, en un sentido «local» o «espacial", según el cual el vacío sería el espacio libre y carente de contenido material, lógicamente necesario para postular la posibilidad del movimiento; segundo, como una noción dependiente de la idea de límite, según la cual el vacío sería tanto el espacio "externo" al universo de lo que es, con el que limitaría éste si no fuera infinito, como el intervalo hueco y falto de contenido que delimita las cosas que son, constituyendo, por tanto, el fundamento no sólo del movimiento, sino también de la multiplicidad y del cambio; en tercer y último lugar, Meliso entiende el vacío como una especie de oquedad interna a los cuerpos que posibilitaría, en función de que sea mayor o menor, la densidad y la rarefacción de aquéllos. Finalmente, las ideas de Anaxágoras, Empédocles y los pitagóricos no añadirían nada nuevo a lo ya dicho, siendo importantes de todos modos porque dejan clara la distinción entre aire y vacío y reafirman la concepción de éste como el espacio de absoluta incorporeidad que separa y delimita las cosas.

Una vez hecho este sumario, estamos preparados para abordar la concepción que tienen del vacío los primeros atomistas, Leucipo y Demócrito, quienes fueron los primeros que no sólo postularon su realidad óntica y existencial (junto con Juto y los pitagóricos), sino que lo convirtieron en una pieza capital de su cosmología.

Para entender bien la teoría atomista, debemos advertir que se presenta como una respuesta a la metafísica eleata, en concreto, la de Meliso, de cuya doctrina acepta algunos postulados, mientras rechaza otros. Según el testimonio de Aristóteles ${ }^{33}$, Leucipo recoge el guante lanzado por el eleatismo de

3367 A 7 DK (Aristóteles, Sobre la generación y la corrupción, I 8, 325a23): «Leucipo creyó tener unas razones que, expresadas en forma coincidente con la percepción, no refuraban ni el nacimiento ni la corrupción ni el movimiento ni la pluralidad de los seres. Haciendo tales concesiones a los fenómenos sensibles y asimismo a los que postulan la unidad [en concreto, Meliso], porque no podría existir el movimiento sin el vacío, dice que el vacío no es y que nada hay en el ser que no sea, pues lo que realmente es, es completamente plenom. 
Meliso al postular las condiciones lógicas que debe cumplir el ser, así como los requisitos necesarios para que pudieran existir realmente los fenómenos que cotidianamente captan nuestros sentidos, es decir, el movimiento, la multiplicidad y el cambio. Leucipo acepta la argumentación lógica del eleatismo con respecto al ser, pero no queda satisfecho con su postura respecto a los testimonios de los sentidos, que para el atomismo responden a fenómenos tan reales como la unidad, la plenitud, la inalterabilidad o indivisibilidad del ser. Por tanto, para Leucipo y Demócrito existe el movimiento, la pluralidad de las cosas y su generación y corrupción. Ahora bien, si recordamos lo que decía Meliso sobre el movimiento ${ }^{34}$, éste sólo era posible si se postulaba un vacío en el que pudieran desplazarse los cuerpos. De este modo, se hizo necesario para el atomismo la aceptación del vacío como un elemento real en el mismo plano que el ser, de modo que toda explicación de los fenómenos naturales debería tener como base el postulado de dos principios elementales de la realidad: el ser o lo pleno y el vacío ${ }^{35}$. Pero, paradójicamente, no se abandonó la dicotomía eleática entre ser y no-ser, de modo que si lo pleno es el ser, el vacío se define como lo que no es, es decir, como lo carente de todo atributo óntico perteneciente al ser, en especial, la corporeidad, pero salvando dos: el de la existencia, y el de ser un constitutivo primario de la realidad ${ }^{36}$.

34 Cf. supra, n. 11.

35 Estos principios fundamentales han de entenderse, según los testimonios, que se sirven de la terminología aristotélica, como elementos últimos e irreductibles que constituyen el origen, la causa y el fundamento de todas las cosas. Cf. 67 A 1 DK (Diógenes Laercio, Vidas de los filosofos ilustres, IX 31): "Como ya se ha dicho, [Leucipo] afirma que el todo es infinito y que de él una parte está llena y otra vacía, siendo ambas elementos«; 67 A 6 (Aristóteles, Metafisica, I 4, 985b4): “Leucipo y su compañero Demócrito dicen que los elementos son lo lleno y lo vacío, llamando al primero ser y al segundo no ser, y que de éstos lo uno es lleno y sólido, el ser, y lo otro vacío y sutil, el no ser; por eso dicen también que no es más real el ser que el no ser, porque tampoco el vacío lo es menos que el cuerpo. Y que éstas son las causas de los seres, a modo de su materia«; 67 A 10 (Hipólito, Refutación de todas las herejias, I 12): «Leucipo... dice que los elementos son lo pleno y lo vacío«; 67 A 12 (Aecio, Opiniones de los filosofos, I 3, 15): «Leucipo de Mileto dice que principios y elementos son lo pleno y lo vacíon. Cf. también sobre Demócrito, 68 A 38, A 40.

3667 A 8 (Simplicio, Fisica, 28, 4): "[Leucipo] afirmaba que el ser no existe en mayor medida que el no ser y que ambos son igualmente causa de las cosas que llegan a ser. Pues, suponiendo sólida y plena la esencia de los átomos, decía que son el 'ser' y que se mueven en el vacio, al que llama 'no ser', añadiendo que éste existe no menos que el ser«; 68 A 38 (Simplicio, Fisica, 28, 15): «De la misma manera, también Demócrito de Abdera, el compañero de Leucipo, consideraba principios a lo pleno y lo vacío, de los cuales al uno llamaba ser y al otro no ser «; $68 \mathrm{~A}$ 40 (Hipólito, Refutación de todas las herejias, I 13, 2): "[Demócrito] dice lo mismo que Leucipo 
Así, y tras la aceptación ontológico-existencial del vacío, Leucipo y Demócrito pueden explicar uno de los fenómenos de la naturaleza: el movimiento. Pero, ¿cómo explicar la pluralidad y el cambio sin traicionar los postulados eleáticos sobre la unicidad del ser, reputados como verdaderos? La clave la vuelve a dar Meliso, quien, intentando ofrecer una prueba de que el ser sólo puede ser uno, llegó a afirmar que si hubiera una pluralidad de seres, éstos tendrían que ser como lo uno ${ }^{37}$, además de que no habría dicha multiplicidad sin un vacío que los dividiera ${ }^{38}$. Así, Leucipo solo tuvo que invertir el signo de esta afirmación y convertirla en el fundamento de su explicación de la multiplicidad: los seres que componen el universo (plantas, animales, rocas, astros, etc...) no se corresponden con las características del ser eleático (plenitud, corporeidad, inalterabilidad, indivisibilidad, eternidad, impenetrabilidad, continuidad, unicidad...), tampoco los elementos tradicionales (agua, aire, tierra y fuego), luego hay que postular una pluralidad de entes que sí cumplan con los requisitos del ser parmenídeo ( $\mathrm{y}$ con la exigencia de Meliso), y, a la vez, respondan a la multiplicidad de la naturaleza. Esos entes son los «átomos».

Los átomos (aÃ-tomoi, lit. «in-divisibles») ${ }^{39}$ son una infinitud de cuerpos extensos, compactos, plenos, impenetrables, inmutables, impasibles, carentes de cualidades sensibles, invisibles por su tamaño y en perpetuo movimiento, que poseen ilimitadas formas, figuras, orientaciones, disposiciones y tamańos, y que conforman la totalidad de las cosas mediante sus colisiones, contactos, reuniones y disoluciones ${ }^{40}$. Constituyen la verdadera realidad última del ser, de lo pleno; fuera de ellos, sólo hay vacío.

sobre los elementos: que son lo pleno y lo vacío, llamando a lo pleno 'ser' y a lo vacio 'no ser' «; 68 A 44 (Hermias, Ridiculización de los filósofos paganos, 13): «Según Demócrito . . . son principios el ser y el no ser, y el ser es pleno mientras que el no ser es vacío "; $68 \mathrm{~A} 45$ (Aristóteles, Fisica, I 5, 188a): «Demócrito afirma [que los principios] son lo sólido y lo vacío, de los cuales considera al primero como ser y al segundo como no ser«; 68 B 156 (Plutarco, Contra Colotes, 1108 F): "[Demócrito afirma que] 'el algo no existe en mayor medida que la nada', denominando 'algo' al cuerpo y 'nada' al vacío, por cuanto que éste posee una cierta naturaleza y realidad propian.

3730 B 8: Pues si hubiera muchos seres, tendrian que ser tales como yo aseguro que es lo uno.

$38 \quad 67$ A 7 (Aristóteles, Sobre la generación y la corrupción, I 8, 324b35): «A algunos de los antiguos les parecía que lo que es, es necesariamente uno e inmovil, pues, por un lado, creían que no hay vacío, y, por otro, que no es posible el movimiento al no haber un vacío separado. Ni habría tampoco multiplicidad de cosas, si no hay nada que las divida".

39 Según Dionisio de Alejandría (68 A 43), el nombre de «átomo" se debería «a su indisolubre solidez" (dial thln aĀluton sterro/thta).

40 Sobre la definición y naturaleza de los átomos, cf. 67 A 6, A 8, A 9, A 10, A 14, A 47, 68 A 37, A 42, A 43, A 49, A 57, A 58, y el testimonio citado en E. Orth, "Curae criticae I-II", Emérita, 26 (1958) p. 202. 
Pues bien, postulados los átomos y el vacío como las realidades elementales, Leucipo y Demócrito tienen ya los instrumentos necesarios para explicar tanto la pluralidad de los seres compuestos, como el cambio en ellos. Así, lo primero se debe a la infinita variedad en la distribución, orientación y disposición de los átomos en el vacío ${ }^{41}$, mientras lo segundo, ejemplificado en la generación y la corrupción, a la continua unión y separación de los mismos gracias al vacío existente entre ellos ${ }^{42}$.

Por tanto, tenemos ya el marco en el que situar el concepto atomista de vacío. Así, el vacío es, en primer lugar, la condición lógica de posibilidad necesaria para la explicación de los fenómenos sensibles: movimiento ${ }^{43}$, multiplicidad y cambio ${ }^{44}$. A partir de ahí, el vacío desempeña en la teoría atomista un papel cosmológico fundamental, que se puede definir en dos ámbitos: primero, $y$ en un plano universal, el vacío es un espacio infinito ${ }^{45}$ con entidad real, cuya

41 Cf. 67 A 6, 68 A 37.

42 Cf. 67 A 7.12-18.

4367 A 19 (Aristóteles, Física, IV 6, 213b2-7): «Los primeros no llegan ni a las puertas del problema, sino más bien los que afirman que existe [el vacio], pues dicen, en primer lugar, que de otro modo no habría movimiento local (siendo éste el desplazamiento y el aumento); en efecto, no parece que pueda haber movimiento si no hay vacío, pues es imposible que lo lleno reciba algo«; 68 A 58 (Aristóreles, Física, VIII 9, 265623-29): «De modo similar piensan también aquellos que, sin aducir una causa de esta clase [del movimiento], recurren al vacío para explicar el movimiento, pues también ellos afirman que la naturaleza se mueve según un movimiento local, ya que un movimiento a través del vacío es un desplazamiento, como si fuese en un lugar, y piensan que los otros movimientos no pertenecen a las cosas primeras sino a las que provienen de ellas, pues dicen que los procesos de aumento, disminución y alteración sólo se efectúan por la combinación y separación de átomos» [trad. de G. R. de Echandía].

44 Algo en lo que coinciden la mayoría de los estudiosos. Cf., por ej., S. Sambursky, $E l$

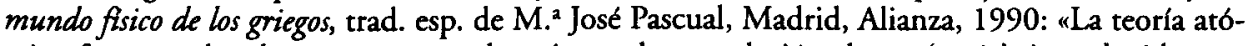
mica fue completada con un segundo axioma, la postulación de un 'vacío', introducido con rigurosa consecuencia en la imagen del cosmos como una realidad independiente. De nuevo este supuesto se apoya en la plausibilidad: dado que la materia está compuesta de átomos, de partículas últimas, inmodificables, todos los cambios deben ser el resultado de sus movimientos y prerrequisito para éstos es el vacío, un espacio completamente carente de materia por el que una partícula pueda desplazarse de un lugar a otron.

4567 A 15 (Aecio, Opiniones de los filosofos, I 18, 3): «Leucipo, Demócrito y Epicuro afirman que los átomos son infinitos en número y el vacío infinito en extensión". Como perfectamente señala $\mathrm{R}$. Mondolfo ( $E$ linfinito en el pensamiento de la antigüedad clásica, Buenos Aires, Eudeba, $1971^{2}$, pp. 287 y 290), la premisa de la infinitud espacial del vacío en el atomismo deriva del concepto de infinitud numérica, es decir, de la idea de una multiplicidad infinita de mundos, que son a su vez infinitas congregaciones de átomos infinitos. Si hay un número infinito de átomos, es necesario que exista un infinito número de intervalos vacíos cuya suma resulte en 
carencia de corporeidad permite el movimiento libre de los átomos ${ }^{46}$, los cuales forman innumerables mundos mediante su concentración en torbellinos ${ }^{47}$. En este sentido, es posible que Leucipo y Demócrito concibieran el vacío como una especie de espacio externo, aparte de cada mundo, que sirviera como referente locativo de éstos en el todo universal ${ }^{48}$. En segundo término, y a escala interna, el vacío es la ausencia permanente de materia entre átomos en virtud de la cual éstos se distinguen individualmente entre sí $^{49}$, a la vez que posibilita

una extensión espacial indefinida: "Así pues, como la realidad del espacio puro (vacío) era afirmada sobre todo en su función de intervalo necesario para la existencia y la acción recíproca de los plenos (átomos), así también la infinitud de él era concebida en conexión con la infinita multiplicidad de los átomos, como suma de intervalos infinitos. En conclusión, pues, toda la infinita extensión de la realidad universal era esencialmente pluralidad infinita de seres reales singulares y sólidos, en cuanto indivisibles e impenetrables; y de espacios intersticiales reales en cuanto interpuestos necesariamente entre sólidas realidades corpóreas" (p. 290).

$46 \quad 68$ A 43 (Dionisio de Alejandría, en Eusebio, Preparación evangélica, XIV 23, 2.3): “En efecto, los que llaman átomos a ciertos incorruptibles y minúsculos cuerpos de cantidad innumerable, y proponen un espacio vacío ilimitado en extensión, dicen que los átomos se mueven en el vacío al azar y chocan espontáneamente unos con otros debido a su ímpetu desordenado“; 68 A 49 (Galeno, Sobre los elementos según Hipócrates, 1 2): «Los átomos, siendo todos pequeños cuerpos, no tienen cualidades, mientras que el vacío es un espacio en el cual todos esos cuerpos se mueven hacia arriba y hacia abajo eternamente, o bien se entrelazan de algún modo entre ellos, o bien chocan y rebotan, y se disgregan y se agregan de nuevo entre sí en compuestos semejantes".

4767 A 1 (Diógenes Laercio, Vidas de los filósofos ilustres, IX 30-3): "Y los mundos [según Leucipo] se originan del modo siguiente: por segmentación de lo infinito, se desplazan muchos cuerpos con toda clase de formas hacia un gran vacío. Al congregarse éstos, al reunirse, se produce un torbellino, en el que, chocando unos con otros y girando en todos los sentidos, se va separando lo semejante con lo semejante. Cuando ya no pueden girar en equilibrio, por su gran número, los livianos se dirigen, como agitados, hacia el vacío exterior, mientras que los demás se quedan juntos y, entrelazados, toman el mismo camino y producen, primero, una estructura esféricam [trad. de A. Bernabé] ; 67 A 10 (Hipólito, Refutación de todas las berejías, I 12): "Y dice [Leucipo] que los mundos se produjeron así: cuando muchos cuerpos, a partir de lo circundante, se reunieron y confluyeron en un gran vacío, chocando entre sí, se combinaron los que tenían figuras semejantes o eran similares en cuanto a sus formas, y enlazándose, dieron origen a los astros" [trad. de M. ${ }^{2}$ Isabel Santa Cruz y N. L. Cordero].

48 Asf lo testimonian Simplicio (Física, 648, 12): «Los partidarios de Leucipo y de Demócrito decían que hay un vacío no sólo en el mundo, sino también fuera del mundo", y Aristóteles (fr. 208 Rose, en Simplicio, Acerca del cielo, 295, 1): “Demócrito piensa que la naturaleza de las cosas eternas son pequefias sustancias infinitas en número; y supone que éstas se hallan en un espacio distinto [de ellas], infinito en extensión. Designa a este espacio con los nombres de 'vacío', 'nada' e 'infinito', y a cada una de las sustancias con el de 'algo', 'sólido' y 'ser'.

49 Cf. R. Mondolfo, op. cit., p. 287: "No hay existencia originaria de una sustancia única, sino multiplicidad infinita (de número, de formas, de tamaños) de elementos, cuya existencia separada viene a desmenuzar en fragmentos infinitos hasta el espacio mismo (el vacío), conce- 
un medio a través del cual éstos, al moverse, puedan unirse y generar cuerpos compuestos $^{50}$, o separarse y disolverlos. Este vacío inter-atómico, a modo de intersticio hueco, se concibe también como el posibilitante tanto de la contracción y compresión de los cuerpos, quienes pierden volumen a costa de ocupar dichos intersticios vacíos en su interior ${ }^{51}$, como de su aumento, al desempeñar el vacío el papel de receptor en el cuerpo de la materia externa que se añade a él ${ }^{52}$. En este mismo sentido, parece que los atomistas pusieron también el vacío en relación con el peso de los cuerpos, siendo éste inversamente proporcional a la cantidad de vacío encerrado en dichos cuerpos ${ }^{53}$, así como con su dureza y blandura, propiedades que dependen de la distribución del vacío en ellos: así, un cuerpo que contiene un mayor número de intersticios vacíos dispuestos de forma irregular, es más denso y, por ende, más duro; mientras que otro cuerpo con una relación proporcionada y simétrica de átomos y vacío es más raro $\mathrm{y}$, por tanto, más blando, aunque contenga menos cantidad de vacío ${ }^{54}$.

bido esencialmente en relación a las distinciones individuales, o sea como serie infinita de innumerables intervalos entre los átomosm.

50 El engarce de los átomos entre sí no supone en ningún caso la disolución de éstos en estructuras mayores. Los átomos se unen, pero no se mezclan, conservando siempre su individualidad en virtud del vacío que existe permanentemente entre ellos; cf. 67 A 7 (Filópono, Sobre la generación y la corrupción, 158, 26): «Demócrito hablaba de juntura, pero no en sentido estricto, cuando afirmaba que los átomos se tocan unos con otros... sino que al hecho de que los átomos estén muy próximos entre sí y que la distancia entre ellos no sea muy grande, a esto lo llamaba juntura; pues ellos están del todo separados por el vacío" [trad. de M. ${ }^{2}$ Isabel Santa Cruz y N. L. Cordero].

5167 A 19 (Aristóteles, Física, IV 6, 213b15-17): "Algunos [cuerpos] parecen contraerse y comprimirse, tal como aseguran que los toneles reciben el vino con los odres, como si el cuerpo se contrajera en los [intersticios] vacíos que hay en éln.

5267 A 19 (Aristóteles, Física, IV 6, 213b18-20): «También les parece a todos que el aumento se produce gracias al vacío, pues el alimento es un cuerpo y es imposible que haya dos cuerpos a la vez [en un mismo sitio]".

53 Obviamente, nos referimos a cuerpos compuestos, no a los átomos, los cuales deben su peso a su tamaño. En cuanto al vacío como condicionante del peso, cf. 68 A 60 (Aristóteles, Acerca del cielo, IV 2, 309a): «En los compuestos, en cambio, (...) vemos que muchos seres más pequeńos son más pesados, como el bronce respecto de la lana; algunos piensan, entonces, que hay otra causa, y dicen: el vacío encerrado en los cuerpos los aligera y hace que, a veces, cosas más grandes sean más ligeras, pues contienen más vacíon; 68 A 135 (Teofrasto, De las sensaciones, 61): «Demócrito distingue lo pesado y lo ligero por el tamaño, ya que, si se discernieran cada uno [de los átomos], aun cuando se diferenciaran por su figura, [cada uno] tendría por naturaleza un peso relativo a su tamaño. Sin embargo, en los compuestos es más ligero lo que tiene más vacío, y más pesado lo que tiene menos".

5468 A 135 (Teofrasto, De las sensaciones, 62): "Y en forma similar explica lo duro y lo blando: lo duro es lo denso; lo blando es lo raro (...) Hay una diferencia en la posición y en la 
Finalmente, hay que tener en cuenta que este carácter interválico e individualizable del vacío debe supeditarse necesariamente al límite externo de los átomos, cuya indivisibilidad e impermeabilidad deben ser la garantía última de la conservación del ser. Por eso los atomistas griegos niegan el vacío en el interior de los átomos ${ }^{55}$, pues ello supondría la infinita divisibilidad de la materia (posibilidad que ya puso de manifiesto Zenón de Elea en una de sus aporías ${ }^{56}$ ) y, por tanto, estar sujeta a una desintegración completa. En este sentido, Leucipo y Demócrito postulan lo que Sambursky llama «la ley de la conservación de la materia", según la cual deben existir unas partículas últimas indivisibles sobre las que se cimente la realidad y en las que se detenga el proceso de fragmentación y disgregación, lo cual permite que no haya ninguna pérdida de la cantidad de materia ${ }^{57}$.

En resumen, podemos decir que los atomistas precisaron y desarrollaron el concepto de vacío que habían recibido de la tradición anterior (especialmente, de la tradición eleática a través de Meliso), haciendo de esta noción un pilar fundamental de su doctrina y convirtiéndola en un claro precedente de la moderna idea de vacío como espacio físico carente de toda realidad material.

distribución del vacío entre lo duro y lo blando, lo pesado y lo liviano. Por eso el hierro es más duro y el plomo más pesado, pues el hierro está constituido de forma irregular y tiene vacíos abundantes y grandes, pero en otras partes es denso, si bien en general contiene más vacío; el plomo, en cambio, tiene menos vacío, está constituido regularmente y es semejante por doquier. Por esta razón es más pesado que el hierro, aunque sea más blandom [trad. de M.a Isabel Santa Cruz y N. L. Cordero].

55 67 A 14 (Simplicio, Acerca del cielo, 242, 15): «Estos [Leucipo, Demócrito y Epicuro] decían que los principios, a los que consideraban también átomos indivisibles e inalterables por ser sólidos y estar libres de vacío, eran infinitos en número, ya que afirmaban que la división se produce debido al vacío existente en los cuerpos".

56 Fr. 3: Si hay muchos, los seres son infinitos, pues siempre hay otros en medio de estos seres, $y$ de nuevo otros en medio de éstos, de modo que los seres son infinitos.

5767 A 7 (Aristóteles, Sobre la generación y la corrupción, I 8, 325b5-10): «Empédocles se ve llevado a decir prácticamente lo mismo que Leucipo: existen, en efecto, ciertos sólidos, que son indivisibles; en caso contrario, los poros serían completamente continuos. Pero esto es imposible, pues no podría existir sólido alguno aparte de los poros, sino que todo sería vacío. Es necesario, entonces, que los cuerpos que están en contacto sean indivisibles y que entre ellos exista el vacío, que aquél [Empédocles] llama 'poros' " . Cf. también, Sambursky, op. cit., pp. 1323, y Kirk y Raven, op. cit., p. 568. Dice Sambursky a este respecto: «No hay posibilidad alguna de que haya un vacío dentro del átomo mismo ya que, en tal caso, éste podría verse sujeto a cambios y al influjo físico desde el exterior y, por tanto, podría ser desintegrado. De ahí que la postulación de un vacío como prerrequisito del movimiento de los átomos conduzca inevitablemente a la postulación de la solidez absoluta del átomo mismon (p. 134). 


\section{Bibliografía}

Fuentes:

Diels, H. y KRANZ, W. (eds.), Die Fragmente der Vorsokratiker, 6. ed., Berlín, Weidmann, 1952.

\section{Estudios:}

ALFIERI, V. E., Atomos idea. L'origine del concetto dell'atomo nel pensiero greco, Florencia, 1953.

BAILEY, C., The greek atomists and Epicurus, Oxford, 1928.

BARNES, J., The presocratic philosophers, Londres y N. York, 1982.

Bernabe, A., De Tales a Demócrito. Fragmentos presocráticos, Madrid, Alianza, 1988

Burkert, W., Weisheit und Wissenschaft: Studien zu Pythagoras, Philolaos und Platon, Nuremberg, 1962.

DIJKSTERHUIS, E. J., Il meccanicismo e l'imagine del mondo, dai presocratici a Newton, $2 .^{a}$ ed., trad. ital., Milán, Feltrinelli, 1980.

EDWARDS, P. (ed.), The Encyclopedia of Philosophy, 8 vols + Supl., N. York, Crowell Collier and McMillan, 1967.

Foulquí, P., y SAINT-JeAN, R., Dictionnaire de la langue philosophique, 2.a ed., París, Presses Universitaires de France, 1969.

GADAMER, H.-G., "Antike Atomtheorie», en Gesammelte Werke, vol. 5 ("Griechische Philosophie», I), Tubinga, J. C. B. Mohr, 1985, pp. 263-279.

GuTHRIE, W. K. C., Historia de la filosofia griega, trad. esp., 6 vols., Madrid, Gredos, 1986.

JACOB, A. (ed.), Les Notions philosophiques. Dictionnaire, 5 vols., París, Presses Universitaires de France, 1990.

KIRK, G. S., RAVEN, J. E., SChOfIELD, M., Los filosofos presocráticos, 2. ${ }^{2}$ ed., trad. esp., Madrid, Gredos, 1987.

MONDOLFO, R., El infinito en el pensamiento de la antigüedad clásica, 2. ${ }^{a}$ ed., Buenos Aires, Eudeba, 1971.

PeTERS, F. E., Greek Philosophical Terms. A Historical Lexicon, N. York, N. York University Press, 1967.

RIBAS I MASSANA, A., Biografia del vacio: su historia filosofica y cientifica desde la Antigüedad a la Edad Moderna, Barcelona, Destino, 1997.

SAMbURSky, S., El mundo fisico de los griegos, trad. esp. de M. ${ }^{a}$ José Pascual, Madrid, Alianza, 1990. 
SAUnders, S. y Brown, H. R. (eds.), The Philosophy of Vacuum, Oxford, Clarendon Press, 1991.

Sedley, N. E., "Two conceptions of vacuum", Phronesis, 27 (1982) 179-183.

URMSON, J. O., The Greek Philosophical Vocabulary, Londres, Duckworth, 1990.

VV.AA., Los filosofos presocráticos, 3 vols., Madrid, Gredos, 1986.

WIENER, PH. P. (ed.), Dictionary of the History of Ideas, 5 vols., N. York, Scribner's, 1968-1974. 